\title{
The Future of E-book Compared with Textbook in Educational Setting in Kuwait
}

\author{
Ali Mahmoud Buhamad \\ College of Basic Education, The Public Authority for Applied Education and Training \\ Kuwait
}

\begin{abstract}
E-book is one of the educational technology tools that may affect the learning and make it faster and easier. A lot of reasons prevent the instructor from dealing with E-book. The barrier is fact of limited technical instruments available to the teachers. The second barrier is the lack of time and technical background knowledge and the fact that not all subjects are suitable for teaching by E-book as well as location appropriateness The purpose of the study is to examine the acceptance of teachers in using Ebook and utilizing it in the learning environment in Kuwait educational setting. Quantitative data collected through surveys that conducted with teachers who are actively working with E-book in the classroom setting. The participants in this study are 48 high school teachers. This study found that most teachers belief and willing to use E-book in their classrooms, but there are some other reasons prevent them.
\end{abstract}

\section{Introduction}

In the present days, the world has become as one country under globalization control, which means each country complete the other countries form their knowledge, experts, scientists, and scholars. These countries need to improve their abilities by exchange their experiences in a fast and easy way by using technology tools and options. When we have a perfect education, this will reflect on the society success. The countries that are famous for having a high quality of education (the United States, United Kingdom, and Japan) have created their education style for the future. Their systems are simply to renew with current technology, and can mix their technology with education as a baseline to make their society used to dealing with current technology and transfer this experience in their on live situation Using educational technology tools means educators can make the learning process easy and fast in order to develop the receiver's knowledge. Educational technology describes the uses of tools and equipment for educational purposes. It is more than using some tools in the learning process. It is a complete operation that deals with more than one factor: classroom management, teachers, content, learning theories, and tool design by using instructional design models. Some school districts have already started to use technology in their learning setting, especially in early childhood education, such as kindergarten and elementary schools. There is a benefit to using this technology in the first level of education in order to make student used to deal with it in their lives. For example, my generation is facing a problem dealing with hardware and software because this kind of technology that is around us was not available when we grew up. For that, it is very useful to make people live with technology and use it as an important skill in the education process. Ebook is one of educational technology tools that may affect the learning process and make it faster and easier. our technology now imposed it-self in the education system to be a positive method to deliver the knowledge or curriculum content, at the same time the educator depends on and uses it to get the benefits these days. Also, technology is playing an important role in interacting with students because it is providing a good simulation for delivering knowledge. For example, the I pad, PDF files, and E-books are taking the place of regular or printed books

First of all, we should now the meaning of book is a set of printed sheets of paper enclosed between two covers. The book can also be a text in the largest collection of texts. These texts provide and carry a lot of information, knowledge, and experiences. According to Young, 2013, the E-book is actually software. Therefore, it is not real paper that can be touched. Therefore, it will increase the likelihood of losing data or have damaging it and decrease the people abilities to have it.

The E-books as a software are helping to update and grow up contexts and present a good opportunity to have interactive learning resources that can sometimes be substituted for a teacher and do the instructor`s job. Also, we should care about the librarians and make sure to provide them some course training in order to prepare themselves to deal with E-books more than dealing with printed books [29]. E-book is tool provide the educators an opportunity to mix instructional technology tools with learning theories in order to find out how this strategy will affect the teaching process in a positive way. So, it is an application for theory and practice [25].

From the educator perspective or as instructional designers the learning environment that we are working on it should provide multiple formats of materials to explain and deliver the knowledge and leave the selection for the students. It is difficult to dispense with the printed book and working and depending on the digital format because the printed book still has huge number of preferred users. Also, 
the publishers still compete between each other to turn out more books [17].

What distinguishes the new version of books is that the digitally formatted devices are very thin. Also, these devices include more than one option and function, such as: connection to the internet server, practicing the content by quizzes, photo galleries, audio and video recordings, and the ability to update the version of the text [17].

Those benefit are taking in account if you want to compare it with regular textbook. The regular book costs too much and has a poor option. Further, each change by authors the reader needs to get new book, and the book will become an older edition and will not be used for a long time because it missed the new parts [17]. Also, it is heavy to carry.

E-books are important tools that lead teaching and learning to provide great potential [1]. E-book is represented the technology in this term. This kind of modern book is helpful and handy for the academic population because it saves time and effort. It is also easy to get and work on it by using computer tools to find what the writer wants to provide as the idea of his/her study [29].

To make the participants familiars with E-book, it needs to be used more and made a part of daily life such as schools and library. Students have to get training to deal with this kind of tool. In addition, the both teachers and librarians or any educator should be able to work and teach students through it [29].

Applying E-book in schools is reaching the students care but with a large gap between application and preparation. In this case, principals and teachers are facing problems transferring subject content to digital form and receiving the benefit of educational technology [20]. In, addition the old teachers are not familiars of using technology in instruction is the lack of meaningful preparation of applying and using technology and materials, and thus, many professional organizations have suggested that increasing training courses for old teachers is essential in order to motivate and make the teachers more familiar with technology [28]. When requiring teachers to implement a virtual school environment in their curriculum, they voiced an opinion of being very uncomfortable with not being able to see and interact directly with their peers and students, thus creating unwanted barriers and reducing their motivation in the process [16].

A lot of reasons prevent the instructor from dealing with E-book. The first barrier is the fact of limited technical instruments available to the teachers and accessibility to the tools as well. The second barrier is the lack of time and technical background knowledge that impede teachers from incorporating technology in their classrooms specially for imported teachers, and last but not least, the fact that not all subjects are suitable for teaching by E-book as well as location appropriateness [2].

The rational need of our study can be clearly realized after a thorough literature review. We believe more research needs to be done in order to inspect where E-book can be implemented. Also, most studies are very specific; therefore, a need exist to test the generalizability of their results specially in Kuwait. One such research that is fairly recent specifically stated that further studies are needed to test the generalizability of the study that has been done but in different school districts, states, or countries [24].

A common misconception among the education community is that technology implementation in classrooms is just using computers in teaching. The reality of the situation is that technology in general has been used in teaching and education even before the computer was invented. In World War II, the USA incorporated technology in training their young and new troops in using weapons and deploying them fairly quickly with reasonable amounts of readiness [26]. The reason we are mentioning this is to magnify the importance of our research subject and show that the literature on this subject has a rather old history behind it.

The purpose of is proposed study is to examine the acceptance of teachers in using E-book and utilizing it in the learning environment in Kuwait educational setting. This research would answer 1) how the teachers`experience in technology affect the level of comfort of using E-book in their classrooms. 2) How the technology experience of the teacher can help to apply it in his/her classroom. 3) Do teachers think E-book is support their teaching methods. 4) Will this decrease the real book need in the future.

\section{Methods}

\subsection{Participants}

The teachers selected based on a number of criteria which include gender and the experience in technology and their teaching level which supposed to be just high school teachers. In order to have a sample that accurately represent Kuwait, the participants would be chosen in term of friends, family, and relative who were asked to participate voluntarily and visits to schools.

I expected total number of our participants will be $40-50$ high school teachers but the participants who completed the survey were just 48 . By choosing several schools from several school districts, with those teachers have been chosen it gives confidence that I have achieved a reasonable amount of similarity between our sample population and the target population in general. 


\subsection{Instrumentation}

The Likert type scale is used for this study in order to understand the teacher attitude of using the technology that affect the level of comfort of teachers in applying E-book. In order to measure the opinions of the targeted sample; these opinions could be about the degree of agreement or level of occurrence or value [15]. A big factor for us in choosing the method is because it is widely used in the educational field [15]. The survey questionnaires were a descriptive and inferential in one-dimensional matter. By using a 5-point Likert scale. The questionnaire consisted of 10 statements. The answer options included "almost all the time", "frequently", "sometime", "once in a while", and "almost never"

\subsection{Procedure}

The quantitative data collections were conducted via electronic surveys. The teachers were motivated to complete the surveys by researchers personally visiting and explaining to them the potential impact of the successful completion of the study to the development of educational in Kuwait. I used my relationship, friends, and relatives to help us send and complete the survey and also by social media to choose our participants from each school in order to avoid bias in selecting our sample. I predict a $70 \%$ completion of our sample which is an acceptable return rate for our study. The participants had sufficient time to full out the questionnaire, and they used a 4 - 7-minute time frame to answer all 10 questions.

I did not require a name on the surveys; therefore, the sample was anonymous in order to prevent any fear of accountability by the research subjects. Also, I recruited a female researcher to meet with female teachers, and I made sure she is aware of the overall ethics with human subjects and realizes the sensitivities of the culture and traditional issues concerning females in conservative countries.

\subsection{Data Analysis}

For data reliability, I calculated the same data from the final study to ensure that results are highly reliable as possible [23]. I compared the sample of the target population to test the validity of our testing instruments. In order to see what is the level of experience is most likely going to affect the outcome of the level of comfort and enhancement of using Ebook in the learning environment and to explore how much the outcomes relate to the target population, After conducting the survey quantitative data were processed through a descriptive analysis with a percentage of each question of the survey results to describe the current comfort level of using E-book by high school teachers. Using this approach helped to provide systematic information about the reluctance of teachers in using E-book in the classroom setting as a phenomenon. After that, data were analyzed and interpreted accordingly.

\section{Results}

All in all, the results were very much expected and unsurprising as a whole. Although the educators were very much tech savvy, that does not mean that they use their tech know how in the classroom. Also, their students benefited because they are capable of implementing E-book

The completion rate was 100 percent of 48 individuals. There are some important contributing factors that resulted in this maximum completion rate. One such factor is that all the participants are close friends and relatives to the researcher. The nature of the questions. The questions were nonintrusive and conveniently delivered electronically and mobile friendly.

The short amount of time needed to be devoted for the completion of the questions. There were only ten questions that were carefully chosen from a pool of 30 well researched questions that are approved by Faculty members in the Department of Education Technology at the College of Basic Education in Kuwait. The process of answering the questions was very simple and only needed a couple of clicks or taps "depending on the device of the user" to be fully completed.

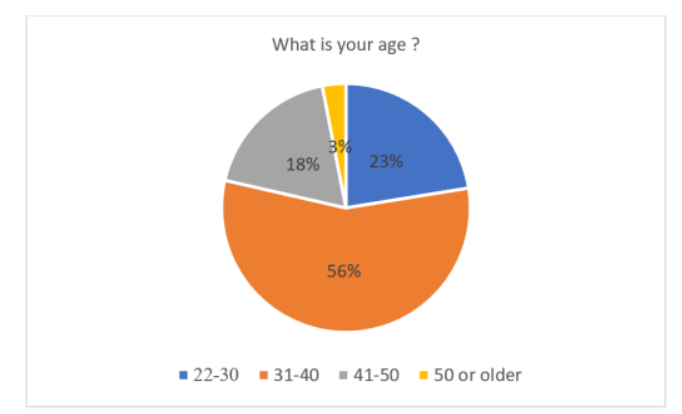

Figure 1. Age groups

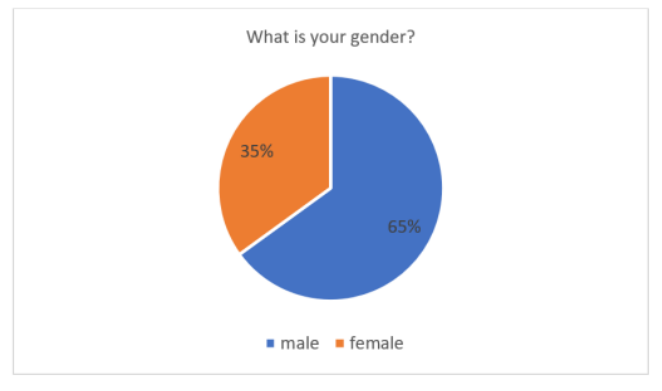

Figure 2. Gender groups 
All in all, the process of completing the questions should not have taken more than ten minutes at the most. Gender and age: The ratio of male participants is $65 \%$ and the female is $35 \%$. However, precisely 56 percent of the participants were of the 31-40 age brackets. This result clarifies the results we eventually viewed later pertaining to their fluency in technology in general. This particular age group is known to be not too old or not too young in regard to the influence of technology in their culture or ways of life.

In order to answer the third research question "How often do you use technology outside of the school environment." I asked about their use of technology outside of the classroom, 47 percent stated that they frequently do so. Also, 29 percent stated that they always use technology. So, in essence, 76 percent have a close relationship to technology in their lives. Since the participants are educators, I asked them about "How often do you research the benefits of education technology in general". Unsurprisingly, 33 percent stated that they sometimes do so while 36 percent stated that they frequently do so. Also, 26 percent revealed that they do so almost all the time.

The result showed the answer of the fifth question in this study " How often do you think E-book is needed inside classroom " just 50 percent of our participants use E-book in the classroom on a daily basis. I also found that most of the teachers either incorporate E-book in their classrooms sometimes or frequently. This could be attributed to other variables such as the availability of technology equipment's, but of course further studies are needed in order to address this possibility.

In regards to the teachers perceptions' How often do you think your students interact normally by using E-book?, the results predictably followed almost the same pattern as before. To be precise, 55 percent of the teachers think that their students always interact normally by using E-book and 30 percent at least sometimes comprehend the content delivered digitally In a straight forward question about the teachers' efforts into helping their self-feel comfortable in using E-book in the classrooms which was about the seventh questions of this study " If you use E-book as technology in the classroom you can save time and effort ", the results were extremely further than earlier responses. To be more specific, 60 percent of the teachers stated that they always use E-book to decrease their tasks and make them selfcomfortable managing their time and efforts and about 36 percent either sometimes or frequently go to the effort of doing so.

About 59 percent of the teachers always help their students understand the content through the use of Ebook while 26 percent help their students frequently and 12 percent at least sometimes help their students do so as well.
In another question about teachers' perceptions of their students 'engage in activities thorough E-book, the result showed that 70 percent of the participants believed that is the case almost all the time. 17 percent say that this is the case regularly while 13 percent stated they think that is the case but only sometimes.

The last question was about How often do you think E-book can be replaced by the paper book in the classroom. The results were also different than earlier replies. 18 percent of the participants reported that they feel comfortable that E-book replaced by the paper book in the classroom, and 41 percent frequently feel the same way while 32 percent only feel that way sometimes.

\section{Discussion}

The printed book is needed for educational purposes because the textbook is the silent teachers of the students, being a reference to students at any time which the E-book can do the something, so, it is a fundamental pillar of the educational process. It is considered as the first source of information and is the shortest way to access the information in an easy, organized and annotated, detailed explanation.

Textbooks represent an important element in the educational process of communication. During the ages of education, printed textbooks and students have accompanied each other; this gives both a good relationship, it considers as a bridge of knowledge that we got from past days. So, when we are talking about knowledge and education, this means that we are talking about printed books.

According to Potts, 2013, the CEO of Amazon, Jeff Bezos thinks that most of the libraries, bookstores, and the printed textbooks are finished. Therefore, regular books will change, and the E-book will take their place.

It is hard guessing about the future especially with affective tool like E-book. So, I will limit this study and mention that the printed textbook will be used in education for next 5 years. I do believe that the role of E-book in education will be similar to what we have now, but a reduction of printed textbooks used in graduate study.

The book in general is one of the keys and bridges between school, assistance to the process, and the objective of public education. It has importance as one of the strongest tools in the formation of the student's mind and helps to achieve correct concepts. It is considered as an ideal way to help students to configure their capabilities and increase their talents. Also, it provides awareness and good behavior and improves their knowledge, various skills, and development of their constructive and behavior. 
How often do you use technology outside of the school environment

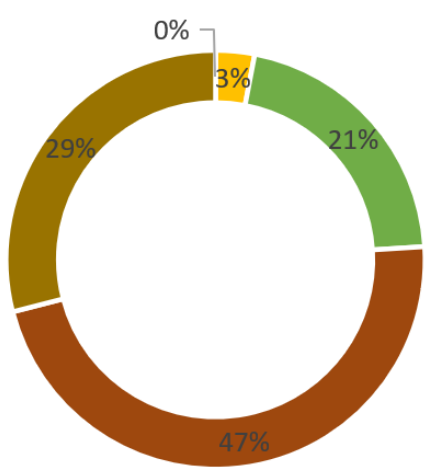

- almost never " once in a while $\quad$ sometimes - frequently " almost all times

Figure 3. Uses technology outside school

How often do you research the benefits of education technology in general

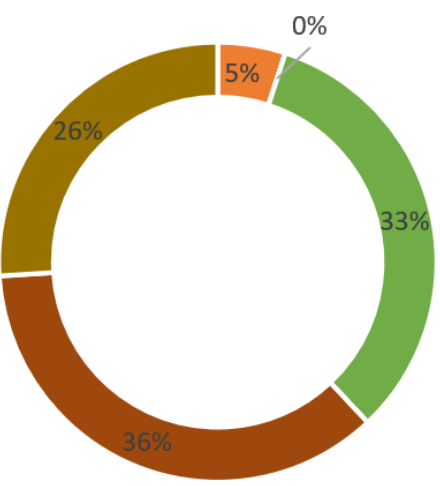

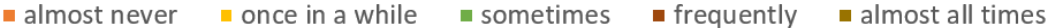

Figure 4. The benefits of education technology in general

How often do you think E-book is needed inside classroom

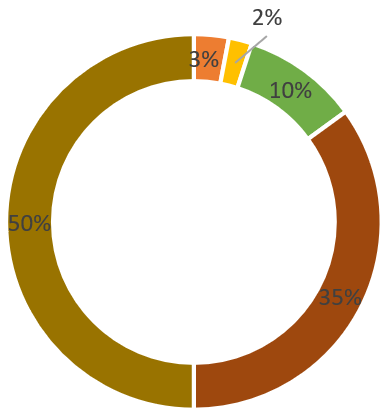

- almost never once in a while mometimes - frequently almost all times

Figure 5. The need of E-book inside classroom 
How often do you think your students interact normally by using E-book

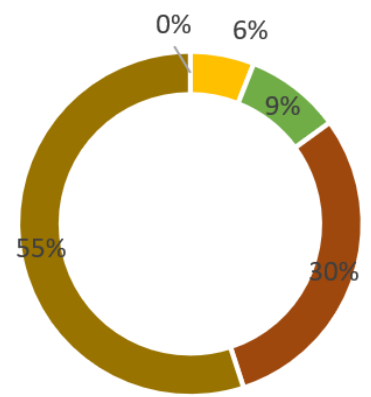

- almost never | once in a while - sometimes - frequently - almost all times

Figure 6. The interacting of students with E-book

If you use E-book as technology in the classroom you can save time and effort

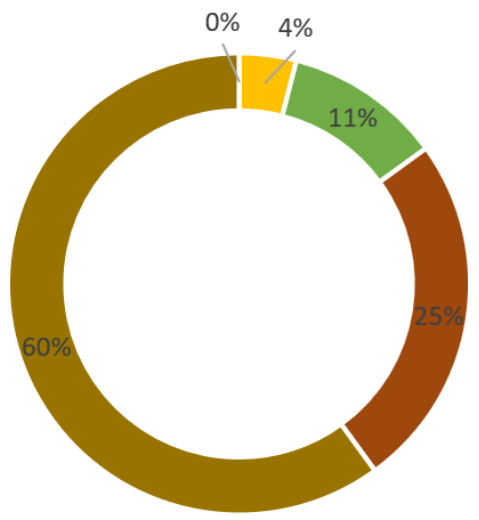

- almost never = once in a while " sometimes - frequently - almost all times

Figure 7. Saving time and effort by E-book

How often do you help your students understand the content through the use of E-book

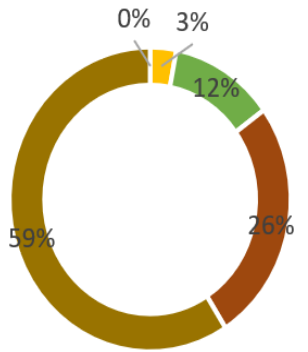

- almost never $\quad$ once in a while $\quad$ sometimes - frequently almost all times

Figure 8. Understanding the content through the use of E-book 


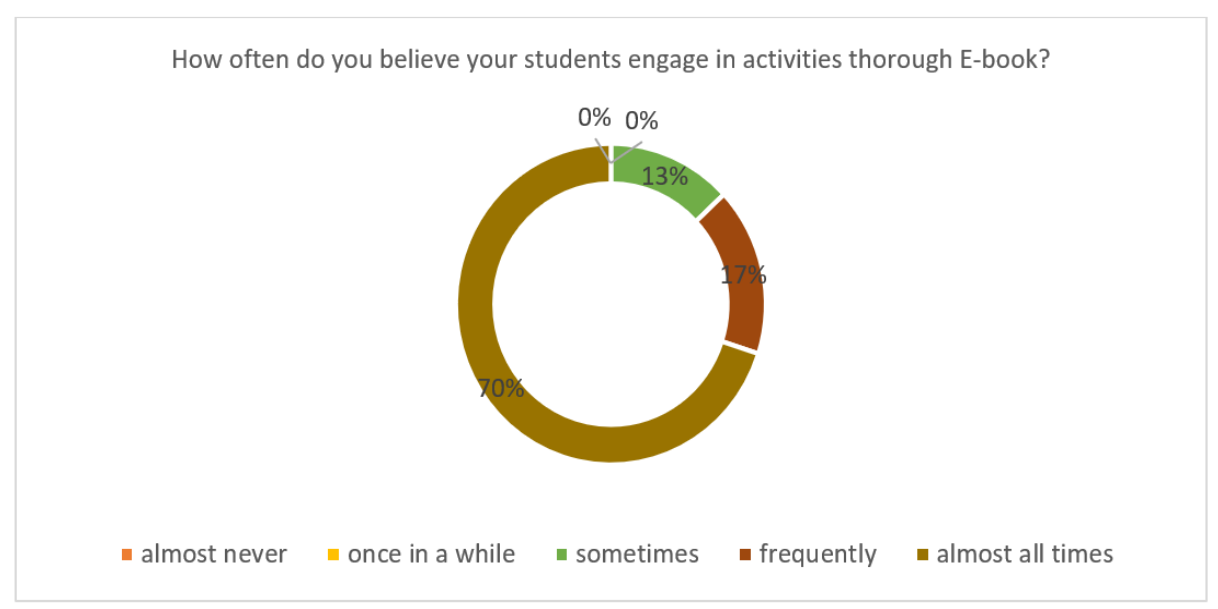

Figure 9. Students engage in activities thorough E-book

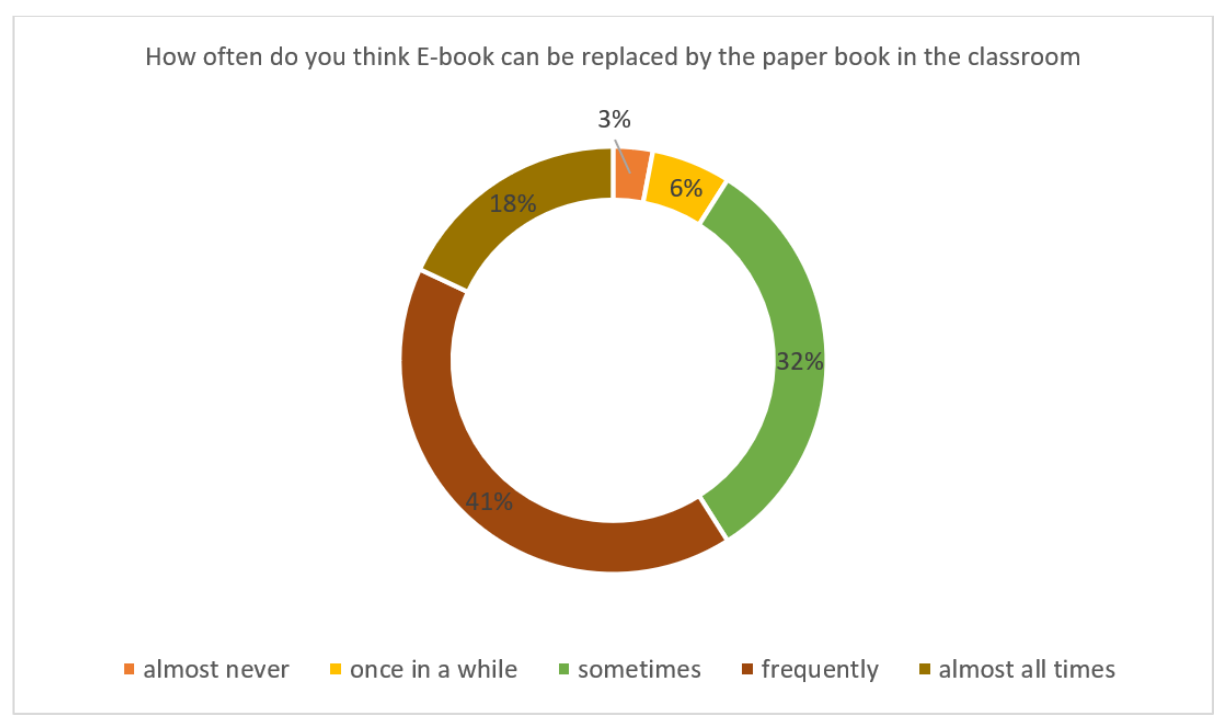

Figure 10. The E-book replacement by the paper book

The E-book has some disadvantage such as, readers have difficult read from the screen of the new generation of books, which is in a digital format. These devices strain the reader's eyes by reading through screens. The readers should be in specific situations with light to keep away from reflections and be able to read; otherwise, they face difficulty in reading with distractions of lighting. When the inventors find out a solution for this major issue, we will see a new generation carrying the E-book to school. But papers are still interesting for kids to tear, use, hold, fold, and crafting [21].

According to Vasileiou, Rowley, and Hartley, [29] the replacement of the printed book will need more time, and the E-book will need more time to be used for educational purposes. As graduate students in educational technology, the faculties in this department still requires printed textbooks to teach us how we can apply technology in the educational field. Which means they should be the first educators encourage use to use this kind of technology. That is supported my idea when I wrote "the printed textbook will be used in education for next three years". At the same time as instructional designers, we should find a good design and work all the tools that facilitate the knowledge delivered.

The results displayed a reliable positive want to use and apply E-books and the amount of motivation the teachers have in incorporating technology in their classrooms to their personal fluency and tech savvies in technology as a whole. The E-books are a bridge to deliver challenging content. Teachers showed a high rate of using technology in their life and are enthusiastic to use it for their teaching purposes because it facilitates their efforts of explaining the needed contents which reflects on the quality of education. The E-books tool is a strategy of learning through the difficulty of assistive devices [18]. At the same time, it is the teacher's task to choose the developing environment that is needed and to select the best way to teach the content [27]. The target of teacher's job is to find a way that gives access for learners to build upon, understand, and discover the classroom content [19]. Changing the method and 
applying E-books can solve the educational issues and bridges the differences between individuals which eventually gives the learners entry to the instructional content.

\section{Conclusion}

The problem that appeared at the end of the study that is the decision is not from the teacher inside the classroom So, I hope that by doing this study, we will acquire the necessary data that will guide the decision makers in ministry of education in Kuwait in making the right choices in regard to E-book in the educational setting, and therefore, we will be making a big impact in the educational field in these nations. This study will clarify the experience in technology and gender as variables that have strong effects on the development of the teaching system and therefore should be taken into account.

\section{References}

[1] Armstrong, C.J., Lonsdale, R., and Nicholas D., (2006) SuperBook: Planning for the e-book revolution. Library and Information Update 5(11): 28-30.

[2] Brush, T., Glazewski, K., \& Hew, H., (2008) Development of an instrument to measure preservice teachers' technology skills, technology beliefs, and technology tarriers. 25(1-2). The Haworth Press.

[3] Chang, C (2007). Study on the quantitative analysis of the development for electronic performance support systems. International J of Instructional Media, 34(3).

[14] Dana, T., Hakverdi-Can, M., (2012) Exemplary science teachers` use of technology. TOJET 11 (1).

[15] Darity, A., (2008). Likert Scale. Vol. 4. 2nd ed. Detroit: Macmillan Reference USA, 2008. p447-448.

[16] Hawkins, A., Graham, C., Barbour, M., (2012) Everybody is their own island: teacher disconnection in a virtual School. IRRODL. 13 (2).

[17] Howard, J., (2013, January 27). For many students, print is still king. The Chronicle of Higher Education. Retrieved from http://chronicle.com/article/For-ManyStudents-Print-Is/136829/

[18] Hune, J., (2004). Technology Application for Children with Behavioral Problems. In R. Ferdig et al. (Eds.), Proceedings of Society for Information Technology \& Teacher Education International Conference 2004 (pp. 4908-4913). Chesapeake, VA: AACE.

[19] Kim, J.H., (2014). Competence in solving problems and blended learning environment in student teaching. In M. Searson \& M. Ochoa (Eds.).

[20] Nordin, N., Yusof, Y., \& Jusoff, K., (2010) Quantitative analysis of malaysian secondary school technology leadership. Management Science and Engineering. 4(2), 124-130.
[21] Potts, J., (2013, January 2). Printed journalism may be dying, but books still have a future. Retrieved from http://theconversation.edu.au/printed-journalism-may-bedying-but-books-still-have-a-future- 10840 .

[22] Phillips, J. \& Phillips, P., (2012). An introduction to return on investment. In R.A. Reiser \& J.V. Dempsey. Trends and Issues in Instructional Design and Technology (3rd ed.). (pp. 105-115). Boston. MA.

[23] Plessis, A. \& Webb, P., (2012) Teachers' perceptions about their own and their schools' readiness for computer implementation: A south African case study. TOJET. Turkey. 11 (3)

[24] Reigeluth, C. \& Jo An, Y., (2011) Creating technology-enhanced, learner-centered classrooms: K-12 teachers' beliefs, perceptions, barriers, and support need. Journal of Digital Learning in Teacher Education.

[25] Reiser, R.A., (2012). A History of Instructional Design and Technology. In R.A. Reiser \& J.V. Dempsey. Trends and Issues in Instructional Design and Technology (3rd ed.). (pp. 17-33). Boston. MA

[26] Reiser, R.A., (2012). What field did you say you were in? In R.A. Reiser \& J.V. Dempsey. Trends and Issues in Instructional Design and Technology (3rd ed.). (pp. 1-7). Boston. MA.

[27] Shanmugasundaram, V., Juell, P., \& Hill, C., (2006). Visualizations to address known problems in teaching Java. In E. Pearson \& P. Bohman (Eds.), Proceedings of World Conference on Educational Multimedia, Hypermedia and Telecommunications 2006 (pp. 19831990). Chesapeake, VA: AACE.

[28] Kim, K. Jain, S., Westhoff, G., Rezabek, L., (2008) A Quantitative exploration of preservice teachers' intent to use computer-based technology. Journal of Instructional Psychology. ProQuest Education Journals. p 275.

[29] Vasileiou, Rowley, and Hartley, (2012, February 22) Journal of Librarianship and Information Science. Perspectives on the future of e-books in libraries in universities. Retrieved from http://lis.sagepub.com/content/ 44/4/217.

[30] Young, J.R., (2013, January 27). The object formerly known as the textbook. The Chronicle of Higher Education. Retrieved from http://chronicle.com/article/ Dont-Call-Them-Textbooks/136835/.

[31] Wachira, P. \& Keengwe, J., (2010) Technology integration barriers: urban school mathematics teachers perspectives. Springer Science+Business Media, LLC 2010. 